\title{
Study of a supply chain system with the presence of bullwhip effect
}

\author{
Ayush Shrivastava ${ }^{1}$, Raghavendra Kamath ${ }^{1 *}$, Himanshu Sharma ${ }^{1}$ and Ajitesh Gogoi ${ }^{1}$ \\ ${ }^{1}$ Department of Mechanical and Manufacturing Engineering, Manipal Institute of Technology, \\ Manipal Academy of Higher Education, Manipal - Karnataka-576104, INDIA
}

\begin{abstract}
A study has been conducted to understand the effect of bullwhip phenomenon in a supply chain system. The hypothetical data collected from the study is used to make a model which can be used to simulate the operation of the system with moderate complexity. System dynamics approach is used to create an open loop system. The phenomenon used is slightly modified and empirically analysed to bring down its adverse effect on the system. The results obtained graphically are emphasising the effect of bullwhip on the various levels of the supply chain system.
\end{abstract}

\section{Introduction}

Supply chain management is about managing how goods and services move and it is dependent on flow and storage of raw materials, unfinished goods and finished goods from point of origin to point of consumption. A typical supply chain would consist of three stages- purchase, production and distribution [1]. The systems which are sophisticated, used products may re-enter at any point where residual value is recyclable. The purpose of developing a Generic Supply Chain Model (GSCM) is to provide a deeper understanding of supply chains in terms of both their development and operation management. Models of supply chain seem to concentrate on only one particular aspect like organization structure/strategy or information technology, or human factors. While each of these dimensions is considered crucial in its own right, each factor by itself does not provide a complete and comprehensive view of supply chains and their management. There are many kinds of supply chain systems even though the types of supply chain members are countable [2]. It is believed that feature model gives definitions of such typical members included in a chain and business process activities of them.

An important factor that affects the efficiency of a supply chain system is bullwhip effect. Bullwhip effect is an observed phenomenon addresses the shift of a seemingly steady inventory demand into enhancing demand fluctuation in upstream supply chain. At the order side of supply chain it results in an amplified variation of information regarding demand [3]. The bullwhip effect is a distribution channel phenomenon in which forecasts yield supply chain inefficiencies. This means there will be increasing variations in

\footnotetext{
${ }^{*}$ Corresponding author: crkamath77@gmail.com
} 
inventory in response to changes in market demand as one goes higher up the in supply chain. It has been observed that a small fluctuation in point-of-sale demand will be lead to a big change in demand on the supply side. Building upon this conceptual definition of bullwhip, it fundamentally consists of not only a level of demand distortion, but also the extent of variance amplification [4]. They imply while it is important to know if firm is experiencing demand distortion, it is equally important to know if such demand distortion is accelerating along the supply chain. A particular type of a simulation model was used by Chatfield et al to analyse the effect of stochastic lead times, sharing of quality information at regular intervals in a supply chain pertaining to inventory system [5]. It has been found that above parameters are very significant in mitigating the effect of bullwhip in a supply chain system.

Agrawal et al studied a two echelon supply chain system with key parameters as information sharing and lead time in understanding the bullwhip phenomenon [6]. They observed that minimising lead time is more beneficial compared to information sharing in reducing the effect of bullwhip. Some alternative forecasting methods are also proposed in order to reduce bullwhip effect using different simulated demand patterns [7]. The expected performance of a vendor managed inventory supply chain with a traditional "serially linked" supply chain was compared and the emphasis of this investigation is the impact these two alternative structures have on the bullwhip effect generated in the supply chain [8]. Quantifying and mitigating the bullwhip effect in a supply chain system was also carried out in various systems [9, 10].A number of quantitative models for developing a good supply chain management system [11]. Casual loop diagrams are very much essential in having a strong feedback in systems $[12,13]$. The effect of bullwhip has been quantified in a supply chain system based on the impact of forecasting, lead time and information [14]. Researchers are also working on the effect of information sharing in a supply chain system and its effect on the performance $[15,16,17]$.

\section{Methodology}

This study is carried out based on the model developed by Disney et al using system dynamics approach. This model was used for analysing various ways of minimising bullwhip effect in a manufacturing loop in supply chain system. This loop consists of retailer at one end and supplier at the other end having a manufacturer in between them. The process starts with retailer placing orders with manufacturer based on the needs of the customer. Then manufacturer places order for components with supplier based on retail order. Finally, supplier supplies the components based on the manufacturers order. Once manufacturer receives the components, he produces products as per the retail order and supplies it to retailer. This entire process is explained through a casual loop diagram as shown in figure 1.

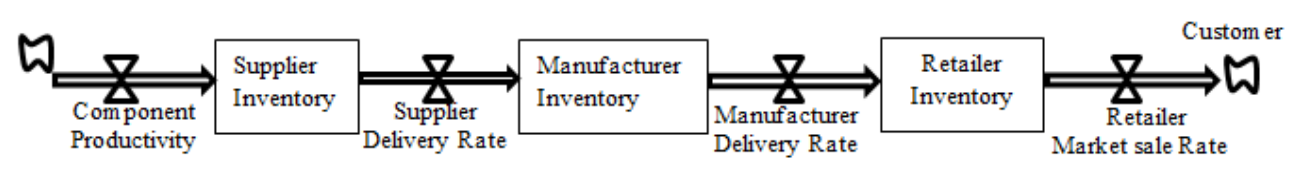

Fig. 1. Casual loop supply diagram of supply chain 
Table 1. State Variables of Supply chain model

\begin{tabular}{|c|c|}
\hline SI & Supplier Inventory \\
\hline MI & Manufacturer Inventory \\
\hline RI & Retailer Inventory \\
\hline
\end{tabular}

There are some assumptions in the created model which include only one type of product in the system, classic inventory situation is considered, products once sold are not taken back. All the capacities like transport, product life cycle and production are unlimited. The primary and secondary variables of the supply chain model are listed in table 1 and 2.

Table 2. Rate variables of Supply chain model

\begin{tabular}{|c|l|}
\hline CP & Components of Productivity \\
\hline SDR & Supplier Delivery Rate \\
\hline MDR & Manufacturer Delivery Rate \\
\hline RMSR & Retailer Market Sales Rate \\
\hline
\end{tabular}

In a product manufacturing scenario, inventory held by the retailer is determined by the consumption and rate of product delivery by the manufacturer. The manufacturer inventory depends on the rate of component delivery by the supplier and rate of remanufacturing products and rate of supply of products to retailer. The supplier inventory depends on production rate of new components and rate of remanufacturing the components and rate of supplying the components to manufacturer. The needs of retailer, manufacturer and supplier all derived from individual sales forecasting and inventory management. Various variables used at three levels of supply chain system are given in table 3 and 4 .

Table 3. Auxiliary variables of Supply chain

\begin{tabular}{|l|l|}
\hline POS & Products Order of Supplier \\
\hline SPDR & Supplier Product Demand Rate \\
\hline IES & Inventory Expected of Supplier \\
\hline FSS & Forecast of Sales of supplier \\
\hline POM & Products Order of Manufacturer \\
\hline MPDR & Manufacturer Product Demand Rate \\
\hline IEM & Inventory Expected of Manufacturer \\
\hline FSM & Forecast of Sales of Manufacturer \\
\hline POR & Purchase Order of Retailer \\
\hline REI & Retailer Expected Inventory \\
\hline RSF & Retailer Sales Forecast \\
\hline
\end{tabular}


Table 4. Constants in Supply chain

\begin{tabular}{|l|l|}
\hline DDS & Delay of Delivery by Supplier \\
\hline DPS & Delay of Production by Supplier \\
\hline IAT & Inventory Adjustment Time \\
\hline STEI & Sustainable Time of expected inventory \\
\hline MAP & Moving Average Period \\
\hline DDM & Delivery Delay by Manufacturer \\
\hline MPD & Manufacturer Production Delay \\
\hline TD & Transportation Delay \\
\hline SPC & Supplier Production Capacity \\
\hline MPC & Manufacturer Production Capacity \\
\hline
\end{tabular}

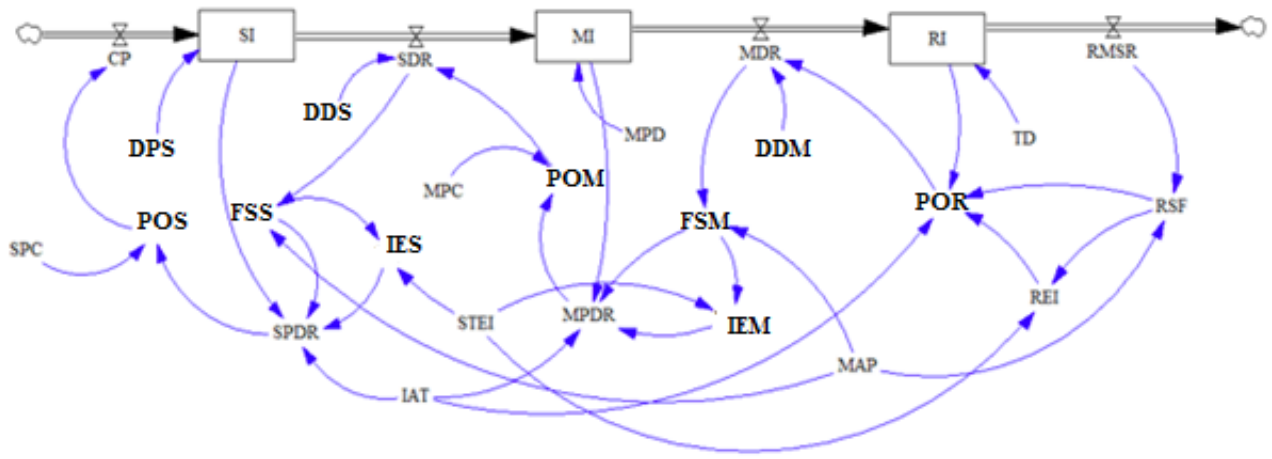

Fig. 2. Supply chain system with an Open loop model

A Supply chain system with an open loop model is shown in figure 2.The purchase order from the retailer is composed of volume of inventory to be adjusted, forecast of sales by retailer. Retailer inventory adjustment is dependent upon the likelihood of having inventory, inventory in real time and inventory adjustment time. Expected inventory by retailer and forecast of sales both are related to the sustainable time of expected inventory. Retailer inventory is a primary variable, the input is the rate of delivery by manufacturer and the output is the consumption in the market. Forecast of sales of retailer is an information delay function of the rate at which sales takes place. Some of the equations used in development of the model for computing retailer, manufacturer and supplier side information are listed below.

Retailer end

$$
\begin{aligned}
& P O R=\operatorname{Max}(0, R S F+(R E I-R I) / I A T) \\
& R I=I \text { Integ }(\text { Delayl }(M D R, T D)-R M S R, 3000) \\
& R E I=R S F * \text { STEI } \\
& R S F=\text { Smooth }(R M S R, M A P)
\end{aligned}
$$

Manufacturer end

$M D R=$ Delay $1(R P O, D D M)$

$M I=\operatorname{Integ}($ Delay $1(S D R, M P D)-M D R, 3000)$

$I E M=F S M * S T E I$

$P O M=\operatorname{Min}(M P C, \operatorname{Max}(0, M P D R)$

$M D R=\operatorname{Max}(0, F S M+(I E M-M I) / I A T)$

$F S M=$ Smooth $(M D R, M A P)$

Supplier end

$$
S D R=\text { Delay } 1(M P O, D D S)
$$




$$
\begin{aligned}
& S I=\operatorname{Integ}(\text { Delay } 1(P P, D P S)-S D R, 3000) \\
& I E S=S S F^{*} S T E I \\
& P O S=\operatorname{Min}(S P C, M a x(0, S P D R) \\
& S D R=\operatorname{Max}(0, S S F+(I E S-S I) / I A T) \\
& S S F=\operatorname{Smooth}(S D R, M A P)
\end{aligned}
$$

In order to measure the bullwhip effect of the various orders under the different conditions, the bullwhip can be quantified and used as given below [17].

$$
B W E=\frac{\sigma_{o}{ }^{2}}{\sigma_{D}{ }^{2}}
$$

where $\sigma_{0}^{2}$ represents the variation in the order rate from retail end to the production end and $\sigma_{\mathrm{D}}{ }^{2}$ represents the variation in the demand encountered at retail end.

\section{Results and discussions}

Lot of information distortion takes places when it moves from one end to the other in a supply chain system. This is one of main reason for presence bullwhip phenomenon. Its detrimental effect can be reduced considerably by sharing of information in an enterprise. When quality information is not shared at any levels be at upstream or at downstream in a supply chain system, enterprise will not have it at the right time and production details can only be predicted based on past data or orders. This has been clearly shown in the simulation of supply chain system obtained using Vensim software. The values in the analysis are obtained by simulation using the software.

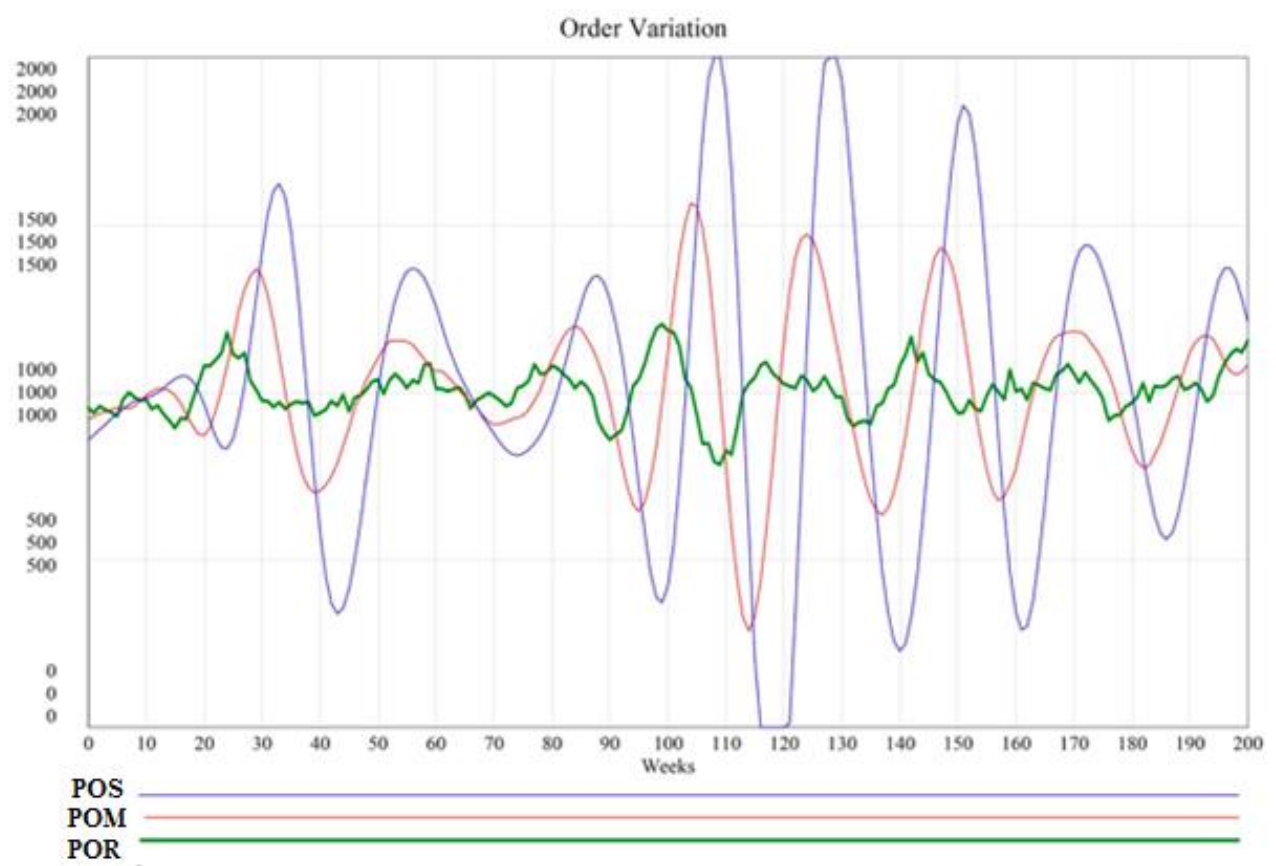

Fig. 4. Baseline model 
The results from the simulation are on the lines of the expected results as shown in figure 4. The graph clearly shows that as the movement takes place from customer end to supplier end, the demand distortion increases which represents higher bullwhip effect. The difference in the peak along the time-axis is caused due to the lead times of the respective levels. Greater the lead time, further will the peaks be but it will also have a smoothening effect as there is more time for the market deviations to settle down.

\subsection{Effect of variation of different parameters on bullwhip effect}

\subsubsection{Varying the Delivery Delay (DDM and DDS)}

It is observed from the simulation that reducing the magnitude of DDM and DDS effectively reduces the Bullwhip Effect as shown in figure 5. It can be inferred that this is due to the possibility of immediate feedback to latter levels which is absent when large delays are prevailing in the system.

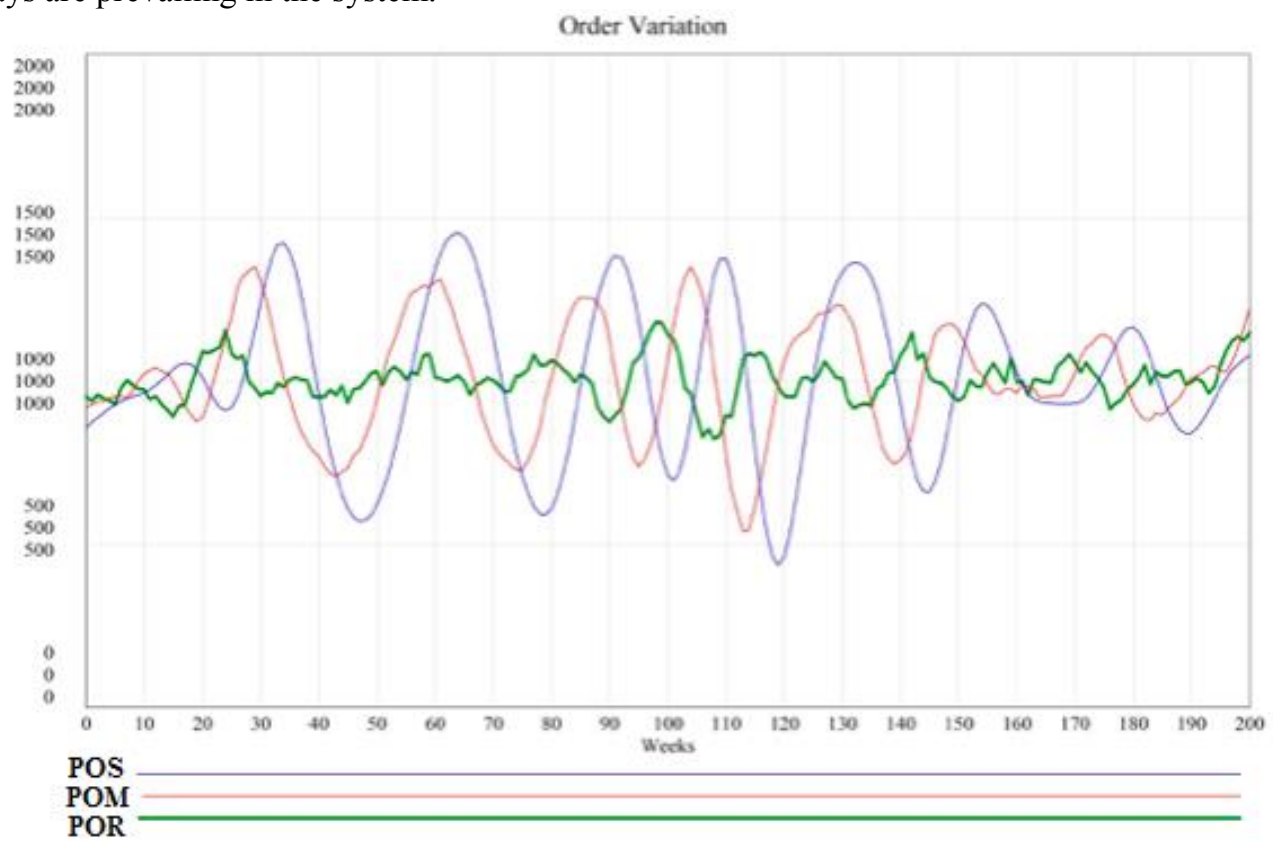

Fig. 5. Effect of varying the delivery delay

\subsection{Varying Moving Average Period (MAP)}

On analysing the effect of varying the forecast period as shown in figure 6 , it is observed that increasing the magnitude of MAP lessens the effective amount of Bullwhip present in the system. The reason for this observation can be explained by the fact that a larger forecast period allows for more accurate predictions of future demands by negating the side-effects from seasonal peaks. 


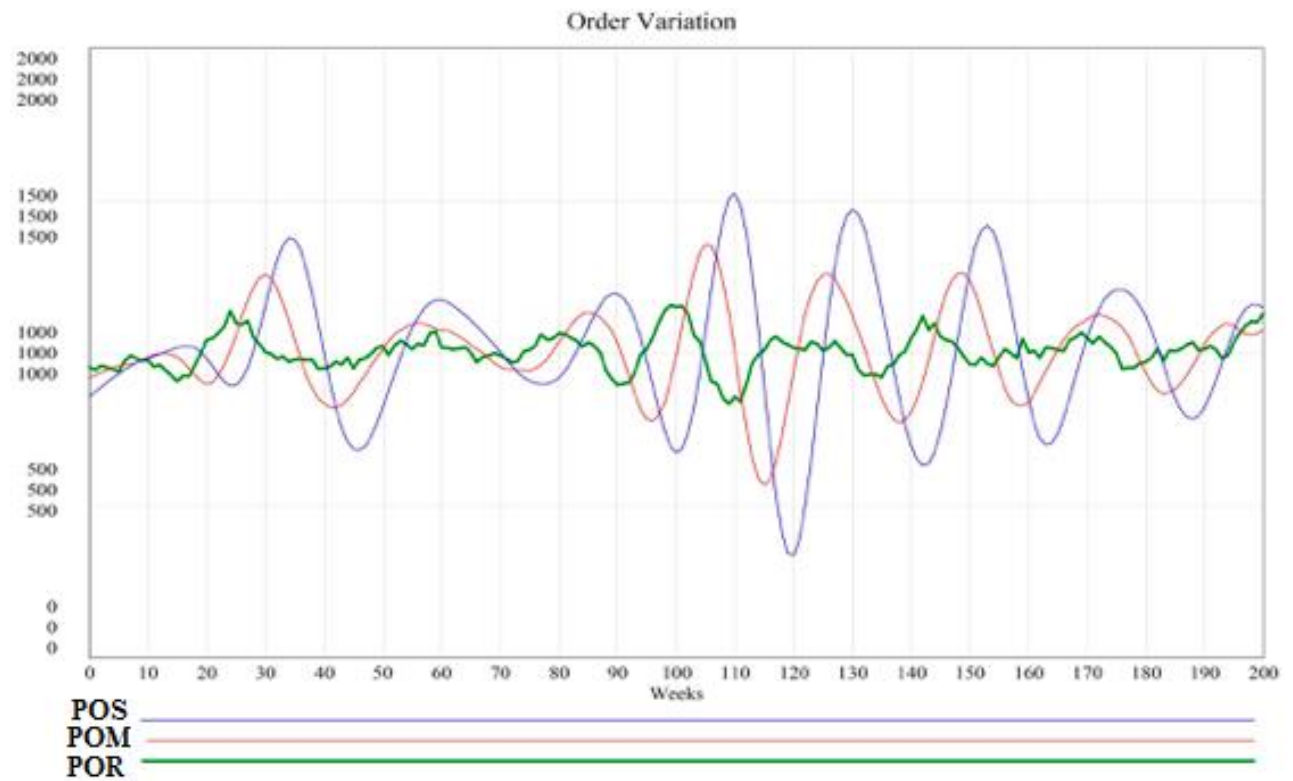

Fig. 6. Effect of varying the forecast period

The impact of different forecast periods on the Bullwhip Effect of a supply chain were observed by conducting a study for a 5-week and a 10 -week time frame on the supply chain modelled for 200 weeks. The results for above two time periods are shown in table 5 and 6.

Table 5. Five week time frame

\begin{tabular}{|c|c|c|}
\hline & POR & RMSR \\
\hline VARIANCE & 5095.962 & 2605.4 \\
\hline
\end{tabular}

$\mathrm{BWE}=5095.962 / 2605.4$

$$
=1.956
$$

Table 6. Ten week time frame

\begin{tabular}{|l|l|l|}
\hline & POR & RMSR \\
\hline VARIANCE & 5105.662 & 2717.562 \\
\hline
\end{tabular}

$\mathrm{BWE}=1.878$

In case of purchase order of the retailer (POR), the distortion in demand is minimum but as we move along supply chain demand distortion increases. This is because the distance between customer demand and retailer demand is one step whereas supplier demand and customer demand is three steps. Lead time and distance between customer demand and each level of supply chain affect the purchase order. So POR has minimum demand distortion, thus shows how bullwhip effect exists in three level supply chain as demand distortion in purchase order of supplier (POS) is highest. 
Retailer market sales rate (RMSR) is the rate at which retailer sells the products, which in turn affects the retailer forecast and there by influencing the retailer demand as shown in above tables 5 and 6 respectively.

\section{Conclusions}

A supply chain has been modelled using system dynamics keeping in mind Bullwhip Effect. This has enabled to model a fairly complex supply chain and shed some light on the interactions between its key parameters. An understanding of the bullwhip effect is necessary to effectively reduce cost involved and optimize the whole structure. There are various parameters that can directly and indirectly affect the supply chain to produce a greater or lesser bullwhip effect.

The results obtained in the form of graphs are interesting from a practical point of view and they helped us to visualise the bullwhip effect and understand the various nuances of the parameters.

\section{References}

1. M. M. Helou, I. N. Caddy, Problems and Perspectives in Management, 4, 4 (2006)

2. S. Umeda, F. Zhang, Proc. Winter Simulation Conference (2010)

3. A. Tanweer, Y. Li, G. Duan, J. Song, 9th Int. Con. Traffic and Transportation Studies, Procedia social and behavioural sciences, 138, 289-297 (2014)

4. A. W. Mackleprang, M. K. Malhotra, J. operations management, 36, 15-32 (2015)

5. D. C. Chatfield, J. G. Kim, T. P. Harrison, J. C. Ha, Production and operations management, 13, 4, 340-353 (2004)

6. S. Agrawal, R.N. Sengupta, K. Shanker, European. J. Operational Research, 192, 576593 (2009)

7. F. Campuzano-Bolarín, A. G. Frutos, M.C.R. Abellón, A. Lisec, Traffic and transportation, 25, 2, 177-188 (2013)

8. S.M. Disney, D.R. Towill, In. J. Operations \& Production Management, 23, 6, 625-651 (2003)

9. D. Fu, C. Ionescu, E. Aghezzaf, R. D. Keyser, Computers and Industrial Engineering, 81, 46-57 (2015)

10. R. Metters, J. Operations Management, 15, 2, 89-100 (1997)

11. G.Srinivasan, Quantitative Models in operations and supply chain management, PHI Learning, 269-273 (2010)

12. A. Radwan, M. Aarabi, Proc. International Conference on Industrial Engineering and Operations Management (2011)

13. J. D. Sterman, Business Dynamics, McGraw Hill, 137-156 (2000)

14. F. Chen, Z. Drezner, J. K. Ryan, D. Simchi-Levi, 46, 3, 436 - 443 (2000)

15. S. E. Fawcett, P. Osterhaus, G. M. Magnan, M. W. McCarter, Int. J. supply chain management, 12, 5, 358-368 (2007)

16. Zahra Lotfi, Muriati Mukhtar, Shahnorbanun Sahran, Ali Taei Zadeh, 4th Int. Conf. Electrical Engineering and Informatics, Procedia Technology, 11, 298-304 (2013)

17. Baris Gunduz, Yaman Barlas,, Ms Thesis (2003) 